\title{
Reasoning the social benefits of mixed land-use and population density in an Indian city
}

DOI:10.36909/jer.ACMM.16301

\author{
Poulomee Arun Ghosh ${ }^{1 *}$, Pratap Manohar Raval ${ }^{2}$ \\ ${ }^{1}$ National Institute of Construction Management and Research, Pune - 411045, India \\ *Email: poulomee16@gmail.com; Corresponding Author. \\ ${ }^{2}$ Professor, Civil Engineering Department, COEP, Pune
}

\begin{abstract}
Mixed land-use and higher population densities are endorsed in many urban planning concepts as crucial elements for urban vitality. They are said to make urban streets active due to the presence of people, leading to public vigilance and improved feeling of safety on streets. Moreover, higher densities and mixed land-uses are also said to promote social interactions and walkability. Indian cities are inherently mix and dense, and therefore, the noted benefits in the literature need to be verified in this local context. In this research, through the empiric al study of eight study areas of Pune, India, the efficacy of social benefits of mixed land-uses and population densities is established. A mixed land-use index for the selected study areas was computed to represent the mixed land-use intensities. Satisfaction levels of the residents regarding the presumed social benefits were surveyed and collated as urban vitality. The relationship between urban vitality and mixed land-uses and population densities is established through curvilinear (quadratic) regression analysis explained by parabola shape. The results of this study reveal that mixed land-uses and higher population densities initially lead to an increase in urban vitality to an extent and then reduce again with intense mixed land-use and high population density. Population density between 12000 to 14000 persons per square kilometer is most suited to achieve urban vitality.
\end{abstract}

Keywords: inherent mixed land-use; population density; urban vitality and social benefits; non-linear relationship. 


\section{INTRODUCTION}

Mixed land-use (MLU) and higher population densities are popular due to their diverse and intensive land utilization characteristics that may reduce car use and increase social connection (Bahadure \& Kotharkar, 2015; Grant, 2002; Jacobs, 1961). MLU can be defined as "the extent of coexistence of non-residential uses with residential use in an integrated way within walking distances of homes" (Hirt, 2007).

Segregation of land-uses emerged in the west to safeguard residences from the ill effects of factories during the industrial revolution (Grant, 2002; Herndon, 2011; Hirt, 2007). After world wars, the change in economic patterns led to the encouragement of mixed land-uses as strategies to revitalize the declining parts of the city. The genesis of the modern-day MLU concept is Jane Jacob's (1961) book 'Life and Death of Great American Cities', which criticized the social fallouts of segregated planning.

However, cities in India are inherently mixed with high population density, traditional MLU character, and vibrant streets (Dave, 2010; Williams, 2004). Still, MLU and optimized density is promoted in India's Smart City Mission and Transit-Oriented-Development (TOD) Policy (MoHUA, 2016; MoHUA, 2017). While endorsing MLU practices in India, it becomes essential to evaluate the benefits of MLU stated in western literature in the Indian context. Pune city of India demonstrates this natural MLU and therefore is taken as the case study for this research.

\section{LITERATURE REVIEW}

\section{MLU Background in India}

Indian cities did not practice segregation of uses in the past but evolved from a highly dense and MLU core that existed before British colonization (Spodek, 2013). The British settled in low-density development outside this core area. The plague in 1896 was associated with overcrowding and poor hygiene in the core area, and attempts were made to push out nonconducive trades (Spodek, 2013). However, the Bombay Town Planning Act of 1915, based 
on the concepts of Sir Patrick Geddes, formed the foundation of modern planning in India, allowing natural mixing of land-uses (Guha, 2020). Post-independence, development plans and associated development regulations govern the mostly self-led development (Williams, 2004; Dave, 2010; Kotharkar, et al., 2012). Along with areas developed before and during the British occupation, the cities now portray diverse MLU and density distribution patterns.

\section{MLU, Population Density, and Urban Vitality}

Density and MLU are interrelated. Dieleman \& Wegener (2004) shows that the desirability of a location is a function of accessibility. Therefore more accessible locations have higher population density. Varied commerce and local businesses find subsistence customers in high density areas thereby amplifying MLU in the area (O'Sullivan, 2012; Williams, 2004). MLU is more functional in high densities areas (Mashhoodi \& Pont, 2011).

Based on Jacob (1961), Koe (2013) relates urban vitality to public life in common spaces like streets and parks that enable the users to associate with the places in their neighborhoods. The presence of people in the streets is socially relevant as they make the streets lively and bring about human connection, feeling of safety throughout the day, and vibrancy (Jacobs, 1961).

Urban sprawl owing to car dependency could ultimately lead to social disconnect. MLU locates multiple activities in close proximities that encourage walking and enables interactions (Bahadure \& Kotharkar, 2012). Jacobs-Crisioni et al. (2014) have found that areas with MLU and higher densities are considered to be more attractive to live and work. Nabil \& Eldayem (2015) have found a direct relationship between MLU and connectedness, trust among people, and shared social resources. In predominantly residential areas, nonresidential uses attract a crowd and bring pedestrian movement on the streets, making them lively. In predominantly commercial areas, when establishments are closed, public places could be eerily empty. The presence of residents makes them feel safer at night. Lu, et al. (2009) has determined that MLU and higher density are positively associated with neighborhood vibrancy. Mouratidis (2017) has found that MLU with the density as part of the 
compact city is associated with better neighborhood satisfaction. People present on the streets are natural vigilantes of crime in public places. Anderson (2013) has suggested that mixed commercial and residential areas are associated with lower crime than commercial-only or residential-only zones.

However, Moos (2018) and Dalton (2017) have pointed out that MLU and density can reduce housing affordability and, therefore, social inequality in the absence of distinct affordable housing policies. Mouratidis (2019) suggests that even though compact cities could be beneficial for health, noise and safety negatively affect the residents. Foord (2011) has demonstrated that support required to sustain MLU in a useful form is rarely established. Browning et al. (2010) has found that density has a curvilinear relationship with crime, and after a threshold, crime increases with density. Hence, residents of MLU and high-density areas need to tolerate the lack of privacy, disturbance, litter, lack of open spaces, restricted parking, limited resources, and low community cohesion (Foord, 2011; Neuman, 2005). MLU in Indian cities emerges from dynamic processes, which can also destabilize them. In inherently mixed cities, areas of high MLU, as well as areas of segregated uses, may lack social well-being (Bahadure \& Kotharkar, 2012). The above-mentioned social benefits/detriments are considered as the parameters for urban vitality for this research.

\section{STUDY AREA}

Pune, located in Maharashtra, India, is governed by Pune Municipal Corporation, covering an area of 331.26 square kilometers. It has a population of 3.13 million, according to census 2011 (Pune Municipal Corporation, 2020). Pune evolved from a village settlement fortified in the $13^{\text {th }}$ Century called 'Kasba Pune'. Between 1595 to 1817 , Pune served as an important center for the Maratha Empire (Diddee \& Gupta, 2013; Mundhe \& Jaybhaye, 2017). Many wards or peths were continues to be the location of residence, marketplace, and handicraft production, evident even today (Diddee \& Gupta, 2013; Mundhe \& Jaybhaye, 2017). This 
area, now known as the core area is charecterized by low-rise and extensive vertical mixeduse buildings.

Between 1818 to 1947 , the British established low density areas with educational institutes, hospitals, railway stations etc., outside the core area (Mundhe \& Jaybhaye, 2017). Postindependence, the city's land development is governed by 20 years Development Plans (DP) and the associated Development Control and Promotion Regulation (DCPR). In 2007, separate DP was prepared for the old corporation limits (the limits for 1987 DP called old limit) and the newly extended areas. Figure 1 is the map of Pune showing the planning boundaries.

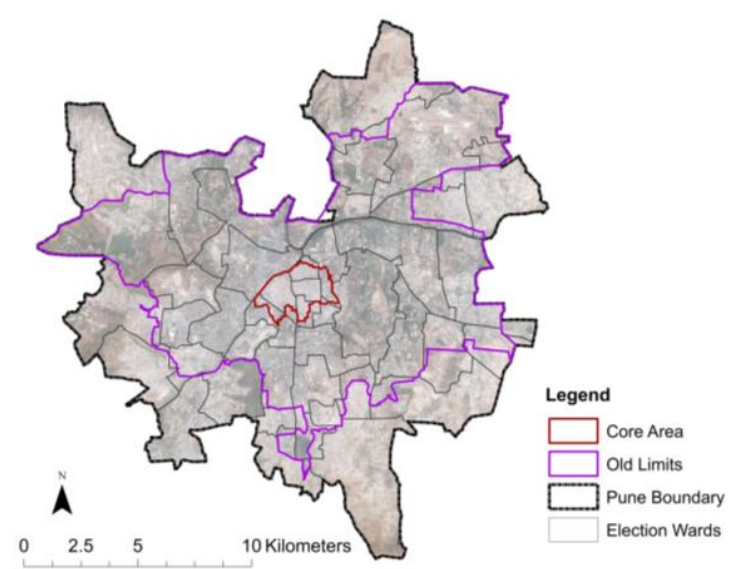

Figure 1 Map of Pune City

Source: Created by Author based on Maxar Technologies, GoogleEarth, 2021 and Development Plan, Pune Municipal Corporation, 2018

Note: Boundary of Pune Municipal Corporation is changed in 2021

\section{Study Area Selection and Mapping}

In similar literature, the number of study areas considered varies from one to 12 (Hoek, 2008;

Bahadure \& Kotharkar, 2015; Sedaghatnia, et al., 2013). Eight areas are selected for this research representing maximum variation in MLU and density patterns. Two of the study areas are from the core area, three from the old limit area, and three from the extended area. Each of these study areas hosts different population densities and portrays a different character of MLUs. A detailed survey was conducted in the study area to note its physical features like road layouts, informal activities, building age and heights, greenery and hygiene 
conditions, and plot-by-plot land-use. The land-use maps of the study areas are shown in Figure 2, which are later used for their MLU indicator computation.

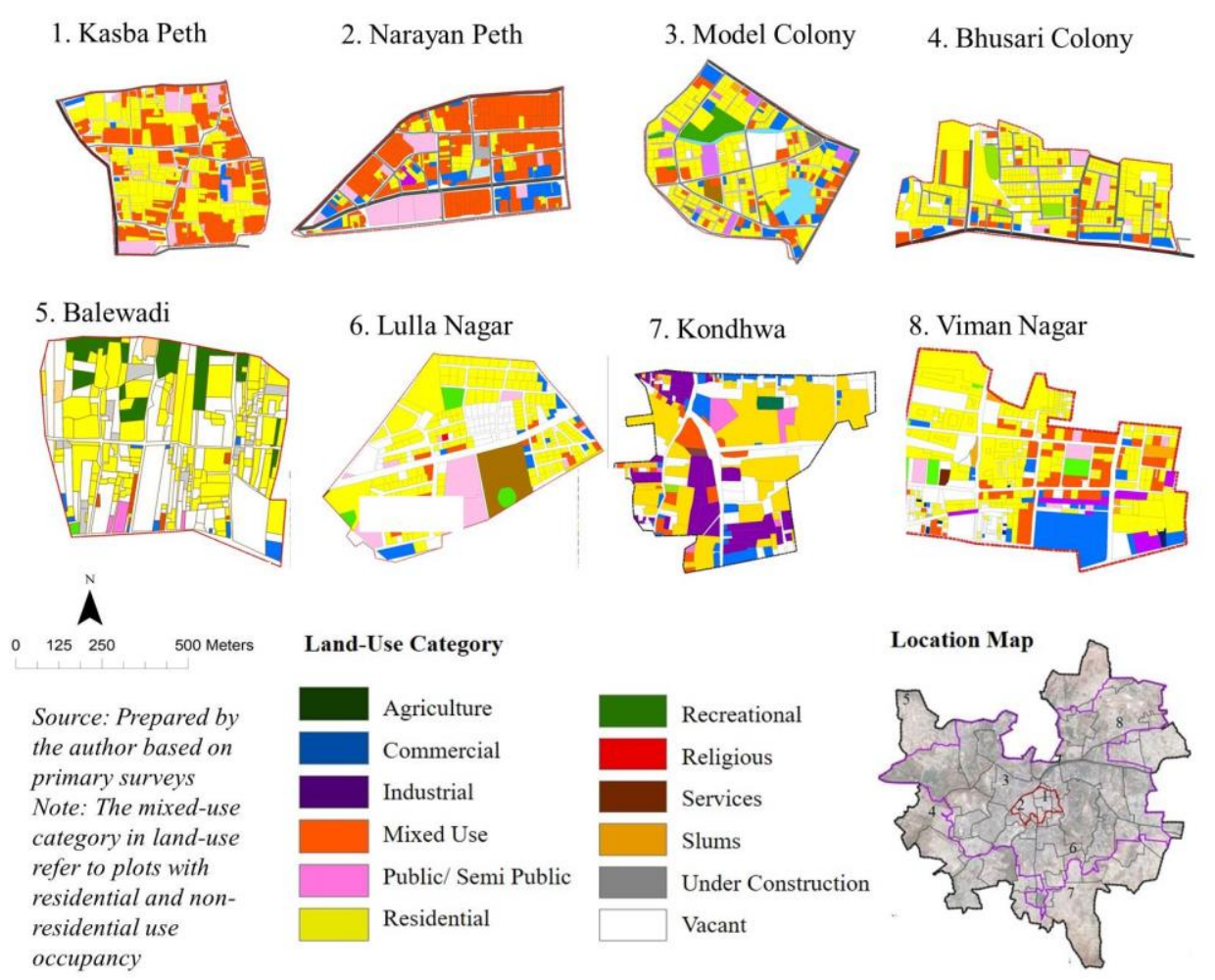

Figure 2 Land-use Maps of Study Areas

\section{METHODOLOGY AND MATERIALS}

\section{Approach}

Selection of the study areas in Pune and documentation of the land-use as shown in Figure 2 was the first step of the research. The second step was to compute the MLU intensity Indicator for the selected study areas based on the land-use data collected. The third step involved the selection of urban vitality/ social benefit parameters. The fourth step was to compute urban vitality indicator based on a satisfaction survey of the residents of the study areas. The fifth and final step was to establish whether there is a statistical relationship between urban vitality and the satisfaction of the residents regarding the social benefit parameters with MLU and the population density of the study areas. 


\section{MLU Intensity Indicator}

MLU intensity would indicate the degree of mixing of diverse land-uses in the area (Song, et al., 2013). Based on the land-use maps shown in Figure 2, the MLU intensity indicators were computed as per the following method:

Mixed-use Percent: Plots shared by different uses (vertically or horizontally) are marked as mixed-use plots. The ratio of the area under mixed-use plots to the total area is used as the indicator (Nabil \& Eldayem, 2015; Yinan, 2009; Hoek, 2008). The following is the equation:

$$
\text { Mixed }- \text { Use Percent }=\frac{\left[\sum_{n=1}^{k} A n\right] * 100}{B}
$$

$k$ : number of mixed-use plots, $A_{n}:$ area of mixed-use plot $n, B$ : Total area of the study area.

Herfindahl-Hirschman Index (HHI): The sum of squares of the proportion of different landuse categories is HHI. It ranges between 0 to 10,000. Lower values are associated with higher MLU (Manaugh \& Kreider, 2013; Song, et al., 2013; Wo, 2019). Following is the equation used for its computation: $\mathrm{HHI}=\sum_{j=1}^{m}(\mathrm{Pj} * 100)^{2}$

$m$ : number of land-use categories, $P j$ : proportion of land-use category $j$.

Areas under each land-use category in Figure 2 were computed in ArcGIS using calculate geometry field. MLU intensity indicators were calculated using the land-use area as per equations (1) and (2). Table 1 shows the indicator details of the study areas.

Table 1 Details of the Study Areas

\begin{tabular}{|l|l|l|l|l|l|l|l|}
\hline Study Area Name & $\begin{array}{l}\text { Area } \\
\text { (sq } \\
\text { km) }\end{array}$ & $\begin{array}{l}\text { Density } \\
\text { (people / } \\
\text { sq km) }\end{array}$ & $\begin{array}{l}\text { Order } \\
\text { by } \\
\text { Density }\end{array}$ & Location & $\begin{array}{l}\text { Mixed- } \\
\text { use } \\
\text { percent }\end{array}$ & $\begin{array}{l}\text { HHI } \\
\text { Index }\end{array}$ & $\begin{array}{l}\text { Order by } \\
\text { MLU } \\
\text { Intensity }^{+}\end{array}$ \\
\hline 1. Kasba Peth & 0.1 & 68194.6 & 8 & Core & 42 & 3897 & 7 \\
\hline 2. Narayan Peth & 0.2 & 35448.9 & 7 & Core & 60 & 1233 & 8 \\
\hline 3. Model Colony & 0.48 & 14395.2 & 6 & Old Limit & 13.28 & 3881 & 6 \\
\hline 4. Bhusari Colony & 0.5 & 8193.97 & 4 & Extended & 9.09 & 6430 & 3 \\
\hline 5. Balewadi & 1 & 3150 & 1 & Extended & 2.17 & 7823 & 1 \\
\hline 6. Lulla Nagar & 0.49 & 12084 & 5 & Old Limit & 4.61 & 5033 & 2 \\
\hline 7. Kondhwa & 0.58 & 4497.12 & 2 & Extended & 7.69 & 4164 & 4 \\
\hline 8. Viman Nagar & 0.56 & 4730 & 3 & Old Limit & 15 & 4087 & 5 \\
\hline
\end{tabular}

*Density of the study areas are based on Census Data (Pune Municipal Corporation, 2020) + Based on the orders of the MLU intensity indicators using Rank Sum (RS) Weights (Danielson \& Ekenberg, 2014) 
According to the literature, MLU intensity and population density of the areas are interrelated. Among the selected study areas, there are small deviances. This is because the areas with a high density and low MLU may be secluded, with roads ending in dead ends. The residential population may be low in areas of high commerce.

\section{Social Benefit and Urban Vitality Indicator}

The parameters of urban vitality (social benefits or detriments of MLU and density), were taken from literature. Total 21 parameters were finalized through a Focused Group Discussion involving citizens' representatives, community organizations, experts from economics, sociology, urban activists, and urban planning. The parameters are grouped under 10 main categories. The list of parameters is indicated in Table 2 in the results section.

The residents' satisfaction regarding the said parameters was surveyed using a 7-point bipolar Likert scale that ranged from extremely dissatisfied to extremely satisfied. The use of subjective measures of satisfaction levels through scales to independently assess a situation is well established in quality of life and well-being research (Marans, 2012; Cummins, 2016). A face scale was used for this survey to visually represent the ranges of the scale (Andrews, 1974; Myers, 2000). Scores ranging from -3 to 3, corresponding to the satisfaction levels of respondents, are used for analysis. Demographic profiles of the respondent's household, ownership status of their residence, housing, and MLU type were also recorded.

A total of 400 samples was targeted, out of which a total of 296 samples are used for analysis. The samples represent roughly $1 \%$ of the estimated population of each study area. For statistical tests involving 'mean' like ANOVA or t-test, a minimum sample size of 30 per area was desired (Rhiel \& Chaffin, 1996; VanVoorhis \& Morgan, 2007). For correlation and regression, while a sample size of 8 is informative, a sample size of 25 and more was desired (Jenkins \& Quintana-Ascencio, 2020). The number of samples per observed variable can be ' $104+m$ ' to ' $50+m$ ' ( $m$ is the number of variables) (VanVoorhis \& Morgan, 2007). This 
research has 21 variables $(\mathrm{m}=21)$ and eight study areas (groups), making the sample size of 296 sufficient to proceed with regression analysis.

For every individual respondent, the urban vitality indicator is computed as a sum of the scores (level of satisfaction) of the 21 parameters as per the following equation:

$$
U_{m}=\sum_{m=1}^{z} s_{m}
$$

$z=$ No. of parameters; $s_{m}=$ Scores of the satisfaction survey of individual parameters; $m=$ Individual parameter. $U_{m}=$ Urban vitality indicator of each respondent

The minimum and maximum possible values are -63 and 63 . Negative values are associated with dissatisfaction.

\section{Analysis Technique for Establishing Relationship}

The MLU intensity and population density orders indicated in Table 1, urban vitality indicator computed using equation (3), and satisfaction levels regarding the parameters are used for the analysis. The possibility of a non-linear relationship is recognized in the literature (Bahadure \& Kotharkar, 2015; Browning, et al., 2010; Wo, 2019). Quadratic regression analysis is conducted to establish the relationships. For quadratic regression, the best-fit line for the data is a curve, i.e., parabola shape. The $\mathrm{R}^{2}$ is the percentage of variance in the independent variable explained by the explanatory variable and indicates the relationship's strength. Analysis of Variance (ANOVA) in regression indicates levels of variability within a regression model and forms a basis for tests of significance. It indicates whether a relationship is statistically significant based on $\mathrm{p}$-value ( $\mathrm{p}^{\prime} .05^{\prime}$ is considered significant) (Yang, 2017). The hypothesis framed for regression analysis are as follows:

Null Hypothesis: $H_{0-M L U-U r b a n}$ Vitality: MLU has no significant effect on urban vitality.

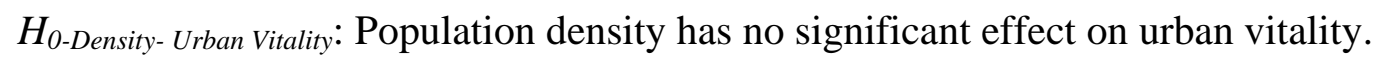

Alternate hypothesis: $H_{1-M L U-U r b a n ~ V i t a l i t y}$ :MLU has a significant effect on urban vitality.

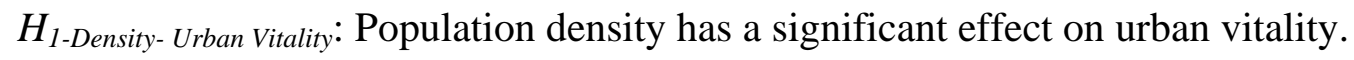




\section{RESULTS AND DISCUSSION}

Figure 3 shows the average Urban Vitality indicator along with their corresponding population density and |MLU intensity order number of the study areas. The best average is 31 out of 63 , indicating that there is still scope for increasing urban vitality. None of the study areas has a negative indicator implying certain amount of satisfaction regarding urban vitality.

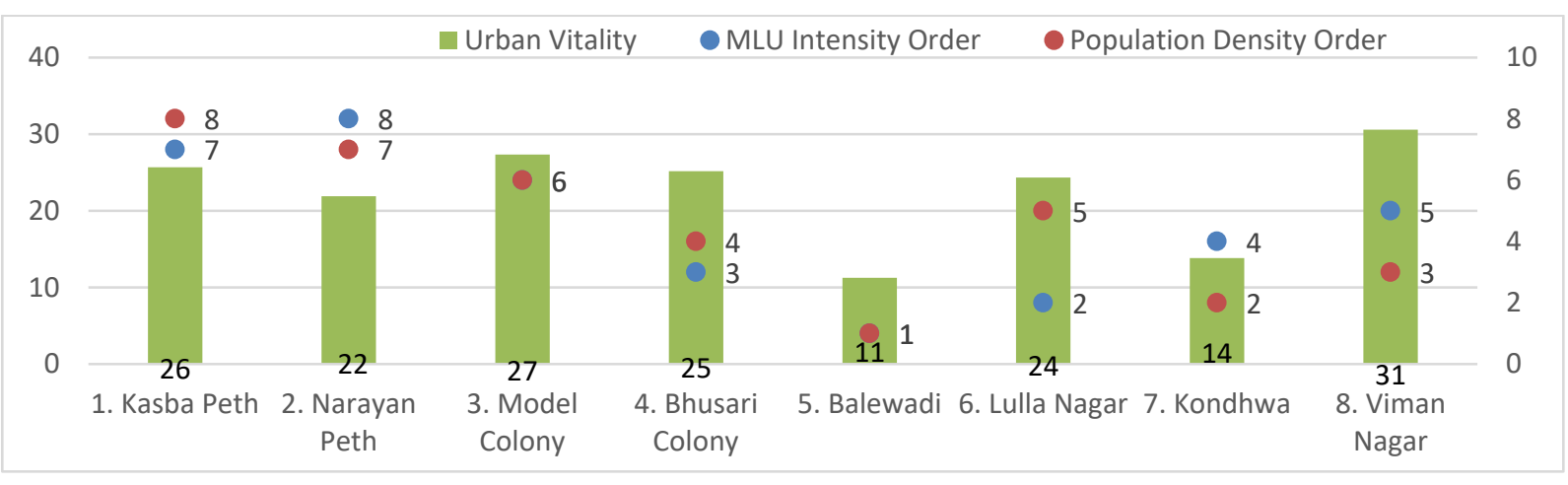

Figure 3 Average Urban Vitality Indicator Score of the Study Sreas

Table 2 gives the values of $\mathrm{R}^{2}$, regression coefficients, and the ANOVA significance level for the regression analysis between urban vitality and the social benefit parameters with MLU intensity order and population density order.

Table 2 Quadratic Regression Analysis Results

\begin{tabular}{|c|c|c|c|c|c|c|c|c|}
\hline \multirow[t]{2}{*}{ Parameters } & \multicolumn{4}{|c|}{ MLU Intensity } & \multicolumn{4}{|c|}{ Population Density } \\
\hline & $\begin{array}{l}\text { ANOV } \\
\text { A Sig. } p\end{array}$ & $\mathbf{R}^{2}$ & $\mathbf{b}_{1}$ & $\mathbf{b}_{2}$ & $\begin{array}{l}\text { ANOVA } \\
\text { Sig. } p\end{array}$ & $\mathbf{R}^{2}$ & $\mathbf{b}_{1}$ & $\mathbf{b}_{2}$ \\
\hline Urban Vitality & $.003 * *$ & .038 & .848 & -.737 & $.000 * * *$ & .059 & 1.014 & -.870 \\
\hline \multicolumn{9}{|c|}{ Visual Appearance (satisfaction with) } \\
\hline Visual Appearance & .319 & .008 & .418 & -.435 & $.000 * * *$ & .077 & 1.311 & -1.234 \\
\hline \multicolumn{9}{|c|}{ Cohesion among Population Groups (satisfaction with a mix of -) } \\
\hline Income Groups & .146 & .013 & .530 & -.559 & .298 & .008 & .432 & -.410 \\
\hline Owners and Renters & .882 & .001 & .056 & -.082 & .548 & .004 & .305 & -.306 \\
\hline $\begin{array}{l}\text { Religion/ Ethnic/ } \\
\text { Language Groups }\end{array}$ & .851 & .001 & -.042 & .009 & .275 & .009 & .443 & -.418 \\
\hline \multicolumn{9}{|c|}{ Interaction with Other Residents (satisfaction with - ) } \\
\hline Interaction & $.016^{*}$ & .028 & .771 & -.695 & $.025 *$ & .025 & .463 & -.327 \\
\hline \multicolumn{9}{|c|}{ Affordability (satisfaction with -) } \\
\hline Property Value & $.001^{* *}$ & .045 & 1.009 & -1.051 & $.000 * * *$ & .079 & 1.170 & -1.285 \\
\hline Cost of Living & .256 & .009 & .444 & -.470 & .080 & .017 & .235 & -.351 \\
\hline \multicolumn{9}{|c|}{ Local Job Opportunity (satisfaction with -) } \\
\hline $\begin{array}{l}\text { Local Job } \\
\text { Opportunity }\end{array}$ & .091 & .016 & .285 & -.393 & $.003 * *$ & .039 & -.065 & -.132 \\
\hline
\end{tabular}




\begin{tabular}{|c|c|c|c|c|c|c|c|c|}
\hline \multirow[t]{2}{*}{ Parameters } & \multicolumn{4}{|c|}{ MLU Intensity } & \multicolumn{4}{|c|}{ Population Density } \\
\hline & $\begin{array}{l}\text { ANOV } \\
\text { A Sig. } p\end{array}$ & $\mathbf{R}^{2}$ & $\mathbf{b}_{1}$ & $\mathbf{b}_{2}$ & $\begin{array}{l}\text { ANOVA } \\
\text { Sig. } p\end{array}$ & $\mathbf{R}^{2}$ & $\mathbf{b}_{1}$ & $\mathbf{b}_{2}$ \\
\hline Parks & $.000^{* * * *}$ & .066 & .919 & -.721 & $.003^{* *}$ & .038 & .739 & -.602 \\
\hline School & .268 & .009 & .468 & -.465 & .095 & .016 & .377 & -.270 \\
\hline Health Care & $.000 * * *$ & .057 & .377 & -.142 & $.000 * * *$ & .084 & -.104 & .391 \\
\hline Convenience Stores & $.014 *$ & .029 & .612 & -.483 & $.000^{* * * *}$ & .070 & .529 & -.276 \\
\hline Banking and ATM & $.000 * * *$ & .052 & .739 & -.552 & $.000^{* * *}$ & .054 & .164 & .070 \\
\hline \multicolumn{9}{|c|}{ Vigilance (Satisfaction with -) } \\
\hline $\begin{array}{l}\text { Safety Watch by } \\
\text { People }\end{array}$ & $.017 *$ & .027 & -.107 & .269 & $.000 * * *$ & .067 & .544 & -.300 \\
\hline Night Time Safety & $.003 * *$ & .039 & .148 & .049 & $.000^{* * * *}$ & .073 & .685 & -.440 \\
\hline \multicolumn{9}{|c|}{ Security (Satisfaction with the absence of -) } \\
\hline Petty Crimes & $.000 * * *$ & .054 & .524 & -.306 & $.007 * *$ & .034 & .399 & -.226 \\
\hline Nuisance Points & .204 & .011 & .467 & -.413 & $.015^{*}$ & .028 & .807 & -.804 \\
\hline \multicolumn{9}{|c|}{ Health (satisfaction with-) } \\
\hline $\begin{array}{l}\text { Security against } \\
\text { Infectious Diseases }\end{array}$ & .123 & .014 & .588 & -.588 & $.002 * *$ & .041 & .963 & -.914 \\
\hline $\begin{array}{l}\text { Scope of Physical } \\
\text { Exercise }\end{array}$ & $.003 *$ & .038 & .777 & -.646 & $.001 * *$ & .048 & .429 & -.220 \\
\hline \multicolumn{9}{|c|}{ Walkability (satisfaction with the ease of -) } \\
\hline $\begin{array}{l}\text { Walking and } \\
\text { Cycling }\end{array}$ & $.000 * * *$ & .056 & .610 & -.798 & $.000^{* * *}$ & .130 & 1.424 & -1.999 \\
\hline $\begin{array}{l}\text { Access to Public } \\
\text { Transport }\end{array}$ & .062 & .019 & .028 & .109 & $.034^{*}$ & .023 & .079 & .227 \\
\hline
\end{tabular}

The regression equation found are $\mathrm{Y}_{\mathrm{Urban} \text { Vitality }}=0.848 \mathrm{X}_{\mathrm{MLU}}-0.737\left(\mathrm{X}_{\mathrm{MLU}}\right)^{2}+9.187+$; and, $\mathrm{Y}_{\text {Urban Vitality }}=1.014 \mathrm{X}_{\text {Density }}-870\left(\mathrm{X}_{\text {Density }}\right)^{2}+5.445$. The scatter plot of urban vitality indicator with MLU intensity order and population density order is shown in Figure 4.

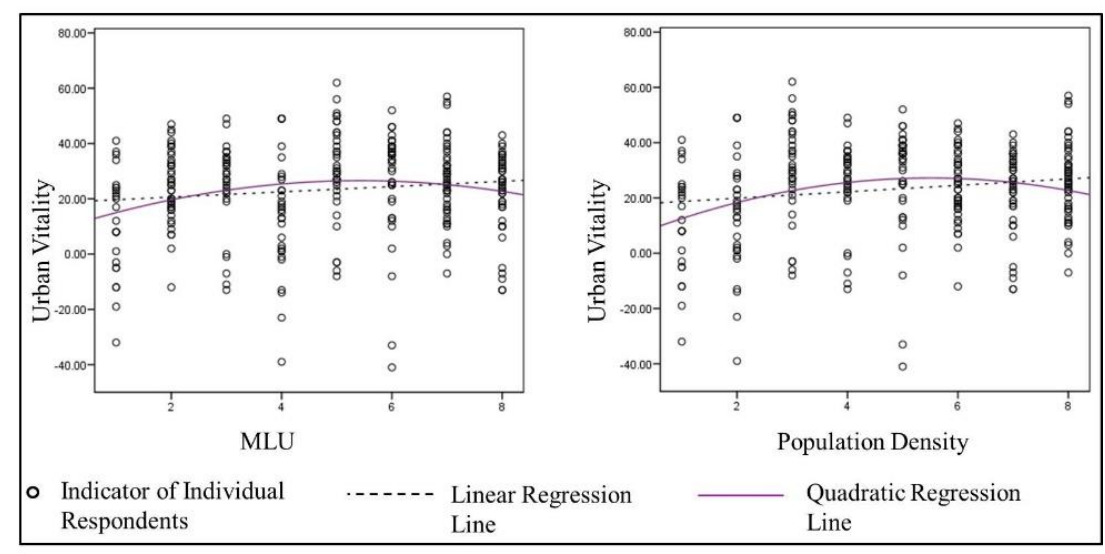

Figure 4 Quadratic Regression analysis scatter plots 


\section{Relationship of Urban Vitality with MLU and Population Density}

In table 2 , as the p-values are less than 0.05 , there is a statistically significant relationship of urban vitality with MLU intensity and population density. As $b_{1}$ is positive and $b_{2}$ is negative, a parabola shape explains the relationships. Null hypothesis $H_{0-M L U-U r b a n}$ Vitality and $H_{0-D e n s i t y-U r b a n}$ Vitality is rejected, and alternate hypothesis $H_{1-M L U \text { - Urban Vitality }}$ and $H_{1-\text { Density- Urban Vitality }}$ is accepted. Urban vitality is low in areas of low MLU and population density, increases with the increase in MLU and population density to an extent (order no. 5, 6 correspondings to a density between 12000 to 14000 people per square kilometer), and then again decreases with Excess MLU and population density. However, relationships are week as $\mathrm{R}^{2}$ is low with MLU and population density explaining only $3.8 \%$ and $5.9 \%$, of the variations in urban vitality.

\section{Relationship of Social Benefit Parameters with MLU}

There is a quadratic relationship (explained by parabola shape) between MLU and interaction with other residents, property value, access to parks, the scope of exercise in daily routine, and ease of walking and cycling. For these parameters, the satisfaction first increases with MLU intensity to an extent and then decreases again with the further rise of MLU intensity. Satisfaction with the access to clinics, stores, banking, public vigilance, and security against petty crimes increases with the increase in MLU intensity. For these parameters, either $b_{1}$ and $b_{2}$ are positive, or even if $b_{1}$ and $b_{2}$ have opposite signs, as the absolute value of $b_{1}$ (without signs) is significantly greater than $b_{2}$, the relationship is close to linear. There is no statistically significant relationship between MLU and visual appearance, parameters under cohesion among population groups, cost of living, local job opportunity, access to schools, absence of nuisance points, security against infectious diseases, and public transport access.

\section{Relationship of Social Benefit Parameters with Population Density}

There is a quadratic relationship (explained by parabola shape) between population density and visual appearance, property value, access to parks, absence of nuisance points, security against communicable diseases, and ease of walking and cycling. For these parameters, the 
satisfaction first increases as population density increases to an extent and then decreases again with the further rise of population density. Satisfaction with interaction, access to clinics, convenience stores, banking and ATM, public vigilance, nighttime security, security against petty crime, and scope for physical exercise increases with the increase in population density. The satisfaction with the cost of living and local job opportunity reduces with an increase in population density. There no significant relationship between population density and access to schools and parameters under cohesion among population groups.

\section{Possible Explanation}

It must be noted that the areas of higher density were from the older core area of the city, while low-density areas are newly developing areas with vacant plots. Areas in the mid-range population density were found to have higher greenery, trees, and parks and could be a possible reason behind the quadratic relationship of visual quality. Though some nonresidential uses may lead to better interactions among residents, too much prevalence attracts outside crowd, which explains the drop in satisfaction in areas with intense MLU. As MLU and population density increase, there are more options of properties driving up satisfaction initially, but in intense MLU and high-density areas, the properties become unaffordable, thereby reducing satisfaction. Areas of high residential density may not offer job opportunities as modern employment centers may be located in business districts explaining the negative relationship. Moreover, the traditional jobs in the core area (which are high density) are reducing (Pethe, 2018). The presence of private health care, banking, and shops of daily needs increase as population densities increase. Multiple establishments could survive offer variety in products in high density areas, leading to increased satisfaction. Visiting nonresidential uses in the vicinity also bring about the opportunity to walk and increase satisfaction. The presence of people in streets due to MLU and the presence of people at audible distances due to high densities increase public vigilance and nighttime security. However, there may be a scope of antisocial activities going unnoticed in very high-density 
areas, leading to dissatisfaction regarding nuisance points. With the increase in MLU and population density, the walkability initially improves as pedestrian infrastructure improves (low-density areas are newer areas where pedestrian infrastructure could be absent). But, as intense MLU may also attract traffic and external visitors, satisfaction reduces. The street infrastructure is insufficient in the high-density areas to accommodate parking, pedestrians, and traffic, explaining the quadratic relationship.

\section{CONCLUSION}

- In Pune, where there is a natural occurrence of MLU, there is a strong relationship between population density and MLU. The increase in density leads to an increase in MLU.

- MLU and population density play a significant role in maintaining urban vitality. But their relationship is quadratic, meaning that the increase in MLU intensity and population in urban vitality increases initially to an extent and then reduces with more intense MLU and excessive population density. Population density between 12000 to 14000 persons per square kilometer is best for urban vitality.

- MLU and population density improve access to convenience shopping, public vigilance, and security against petty crimes. However, the relationship of MLU and population density with access to parks, walkability, and property value is quadratic, explained by a parabola shape due to problems arising due to overcrowding. Higher densities hamper local job opportunities and the cost of living.

- As MLU and population densities explain less than $10 \%$ of the variances in urban vitality and the social benefit parameters, the relationship is weak. Many other factors such as accessibility, age of the area, urban design, location, etc., or personal characteristics may determine factors for urban vitality. 


\section{REFERENCES}

Anderson, J. M., MacDonald, J. M., Bluthenthal, R., \& Ashwood, J. S. 2013. Reducing crime by shaping the built environment with zoning: An empirical study of Los Angeles. University of Pennsylvania Law Review, 161(3): 699-756.

Andrews, F. M. 1974. Social Indicators of persived life quality. Social Indicators Research, 1: 279-299.

Bahadure, S., \& Kotharkar, R. 2012. Social sustainability and mixed landuse, Case study of neighborhoods in Nagpur, India. Bonfring International Journal of Industrial Engineering and Management Science, 2(4): 76-83.

Bahadure, S., \& Kotharkar, R. 2015. Assessing sustainability of mixed use neighbourhoods through residents' travel behaviour and perception: The case of Nagpur India.

Sustainability: 12164-12189.

Browning, C. R., Byron, R. A., Calder, C. A., Krivo, L. J., Kwan, M.-P., Lee, J. Y., \& Peterson, R. D. 2010. Commercial Density, Residential Concentration, and Crime: Land Use Patterns and Violence in Neighborhood Context. Journal of Research in Crime and Delinquency, 47(3): 329-357.

Cummins, R. A. 2016. Subjective Wellbeing as a Social Indicator. Social Indicator Research, 135: 879-891.

Dalton, M. 2017. Density and housing affordability. Working Paper: Coordinating multiple plans research project: 1-24.

Danielson, M., \& Ekenberg, L. 2014. Rank ordering methods for multi-criteria decisions. Joint International Conference on Group Decision and Negotiation: 128-135.

Dave, S. 2010. High urban densities in developing countries: A sustainable solution? Built Environment - The Compact City Revisited, 36(1): 9-27.

Diddee, J., \& Gupta, S. 2013. Pune Queen of the Deccan. Elephant Design Pvt. Ltd., Pune

Dieleman, F., \& Wegener, M. 2004. Compact City and Urban Sprawl. Built Environment, 30(4): 308-323.

Foord, J. 2011. Mixed-use trade-offs: How to live and work in a 'compact city' neighbourhood. Built Environment, 36(1): 47-62.

Grant, J. 2002. Mixed use in theory and practice: Canadian experience with implementing a planning principle. Journal of the American Planning Association, 68(1): 71-84.

Guha, R. 2020. Making Indian Cities Habitable-The Legacy of Patrick Geddes. The India Forum. Retrieved from https://www.theindiaforum.in/article/making-indian-citieshabitable

Herndon, J. D. 2011. Mixed-Use Development in Theory and Practice: Learning from Atlanta's Mixed Experiences. Applied Research Paper: 1- 95.

Hirt, S. 2007. The Mixed-use Trend: Planning attitudes and practices in Northeast Ohio. Journal of Architectural and Planning Research, 24(3): 224-244. 
Hoek, J. W. 2008. The MXI (Mixed-use Index) an instrument for anti sprawl policy ? 44th ISOCARP Congress, Dalian, China.

Jacobs, J. 1961. The Death and Life of Great American Cities. New York: Random House.

Jacobs-Crisioni, C., Rietveld, P., Koomen, E., \& Tranos, E. 2014. Evaluating the impact of land-use density and mix on spatiotemporal urban activity patterns: An exploratory study using mobile phone data. Environment and Planning A: Economy and Space, 46(11).

Jenkins, D. G., \& Quintana-Ascencio, P. F. 2020. A solution to minimum sample size for regressions. Retrieved from https://journals.plos.org/plosone/article?id=10.1371/journal.pone.0229345

Koe, D. d. 2013. Urban vitality through a mix of land-uses and functions. Wageningen University and Research Centre.

Kotharkar, R., Bahadure, P. N., \& Vyas, A. 2012. Compact city concept: It's Relevance and applicability for planning of Indian cities. Opportunities, Limits \& Needs Towards an environmentally responsible architecture. Lima, Perú: PLEA2012 - 28th Conference.

Lu, S., Huang, Y., Shi, C., \& Yang, X. 2009. Exploring the Associations Between Urban Form and Neighborhood Vibrancy: A Case Study of Chengdu, China. International Journal of Geo-Information, 8(4):165.

Manaugh, K., \& Kreider, T. 2013. What is mixed use? Presenting an interaction method for measuring land use mix. The Journal of Transport and Landuse, 6(1): $63-72$.

Marans, R. W. 2012. Quality of urban life studies: An overview and implications for environment-behaviour research. Procedia - Social and Behavioral Sciences, 35: 9-22

Mashhoodi, B., \& Pont, M. B. 2011. Studying land-use distribution and mixed-use patterns in relation to density accessibility and urban form. 18th International Seminar on Urban Form.

MoHUA. 2016. Smart City Features. Ministry of Housing and Urban Affairs, Government of India. http://smartcities.gov.in/content/innerpage/smart-city-features.php

MoHUA. 2017. National Transit Oriented Development (TOD) Policy. Ministry of Housing and Urban Affairs, Government of India. https://smartnet.niua.org/content/4d80e2ff-fab54434-9e3c-53f227a8b575

Moos, M., Vinodrai, T., Revington, N., \& Seasons, M. 2018. Planning for mixed use: Affordable for whom? Journal of the American Planning Association, 84(1): 7-20.

Mouratidis, K. 2017. Is compact city livable? The impact of compact versus sprawled neighbourhoods on neighbourhood satisfaction. Urban Studies, 55(11): 2408-2430.

Mouratidis, K. 2019. Compact city, urban sprawl, and subjective well-being. Cities, 92: 261272.

Mundhe, N. N., \& Jaybhaye, R. G. 2017. Chronological development of Pune from 7582014 AD. International Journal of Environment, Ecology, Family and Urban Studies, 7(5): 33-50. 
Myers, D. G. 2000. The funds, friends, and faith of happy people. American Psychologist, 55(1): 56-67.

Nabil, N. A., \& Eldayem, G. E. 2015. Influence of mixed land-use on realizing the social capital. HBRC Journal, 11(2): 285-298.

Neuman, M. 2005. The compact city fallacy. Journal of Planning Education and Research, 25: 11-26.

O'Sullivan, A. 2012. Urban Economics. McGraw Hill, New York.

Pethe, P. B. 2018. All that glitters is copper: Artisans in Tambat Ali follow a decade-old tradition of making copper vessels. https://www.thehindu.com/society/all-that-glitters-iscopper-artisans-in-tambat-ali-follow-a-decade-old-tradition-of-making-coppervessels/article24054807.ece

Pune Municipal Corporation. 2020. Census data. (Pune Municipal Corporation) Retrieved from pmc.gov.in: https://pmc.gov.in/en/census

Rhiel, G. S., \& Chaffin, W. W. 1996. An Investigation of the Large-Sample/Small-Sample Approach to the One-Sample Test for a Mean. Journal of Statistics Education, 4(3).

Sedaghatnia, S., Lamit, H., Ghahramanpouri, A., \& Mohamad, S. B. 2013. An evaluation of resident's quality of life through neighborhood satisfaction in Malaysia. Environmental Management and Sustainable Development, 2(1).

Song, Y., Merlin, L., \& Rodriguez, D. 2013. Comparing measures of urban land use mix. Computers, Environment and Urban Systems, 42: 1-13.

Spodek, H. 2013. City Planning in India under British Rule. Economic and Political Weekly, 48(4): 53-61.

VanVoorhis, C. R., \& Morgan, B. L. 2007. Understanding Power and Rules of Thumb for Determining Sample Sizes. Tutorials in Quantitative Methods for Psychology, 3(2): 4350.

Williams, K. 2004. Can urban intensification contribute to sustainable cities? An international perspective. City Matters.

Wo, J. C. 2019. Mixed land use and neighborhood crime. Social Science Research, 78: 170186.

Yang, Q. 2017. Regression. In L. A. Schintler, \& C. L. McNeely (Eds.), Encyclopedia of Big Data. Springer International Publishing.

Yinan, Z. 2009. Intensity control in mixed-used new urban area: a case study of the waterfront in Xiasha, Hangzhou. The New Urban Question - Urbanism beyond NeoLiberalism. The 4th International Conference of the International Forum on Urbanism (IFoU) Amsterdam: 1395-1404. 